\title{
A non-synonymous variant $r s 12614$ of complement factor $B$ associated with risk of chronic hepatitis $B$ in a Korean population
}

Jung Yeon Seo ${ }^{1,2+}$, Joong-Gon Shin ${ }^{1,3 \dagger}$, Byeong Ju Youn², Suhg Namgoong ${ }^{2,4}$, Hyun Sub Cheong ${ }^{4}$, Lyoung Hyo Kim ${ }^{4}$, Ji On Kim ${ }^{3}$, Hyoung Doo Shin ${ }^{2,3,4^{*}}$ (D) and Yoon Jun Kim ${ }^{5^{*}}$

\begin{abstract}
Background: Hepatitis B is known to cause several forms of liver diseases including chronic hepatitis B (CHB), and hepatocellular carcinoma. Previous genome-wide association study of CHB risk has demonstrated that rs 12614 of complement factor B (CFB) was significantly associated with CHB risk. In this study, fine-mapping study of previously reported GWAS single nucleotide polymorphism (SNP; CFB rs 12614) was performed to validate genetic effect of rs 12614 on CHB susceptibility and identify possible additional causal variants around rs 12614 in a Korean population. This association study was conducted in order to identify genetic effects of CFB single nucleotide polymorphisms (SNPs) and to identify additional independent CHB susceptible causal markers within a Korean population.

Methods: A total of 10 CFB genetic polymorphisms were selected and genotyped in 1716 study subjects comprised of 955 CHB patients and 761 population controls.

Results: A non-synonymous variant, rs 12614 (Arg32Trp) in exon2 of CFB, had significant associations with risk of $\mathrm{CHB}$ (odds ratio $=0.43, P=5.91 \times 10^{-10}$ ). Additional linkage disequilibrium and conditional analysis confirmed that rs 12614 had independent genetic effect on CHB susceptibility with previously identified CHB markers. The genetic risk scores (GRSs) were calculated and the CHB patients had higher GRSs than the population controls. Moreover, OR was found to increase significantly with cumulative GRS.
\end{abstract}

Conclusions: rs 12614 showed significant genetic effect on CHB risk within the Korean population. As such rs 12614 may be used as a possible causal genetic variant for CHB susceptibility.

Keywords: CFB, Genetic risk scores, Hepatitis B, Korean population, Liver disease

\footnotetext{
* Correspondence: hdshin@sogang.ac.kr; yoonjun@snu.ac.kr

†Jung Yeon Seo and Joong Gon Shin contributed equally to this work.

${ }^{2}$ Department of Life Science, Sogang University, Seoul 04107, Republic of

Korea

${ }^{5}$ Department of Internal Medicine and Liver Research Institute, Seoul

National University, 103 Daehak-ro, Jongno-gu, Seoul 03080, Republic of

Korea

Full list of author information is available at the end of the article
}

\section{$\triangle B M C$}

(c) The Author(s). 2020 Open Access This article is licensed under a Creative Commons Attribution 4.0 International License, which permits use, sharing, adaptation, distribution and reproduction in any medium or format, as long as you give appropriate credit to the original author(s) and the source, provide a link to the Creative Commons licence, and indicate if changes were made. The images or other third party material in this article are included in the article's Creative Commons licence, unless indicated otherwise in a credit line to the material. If material is not included in the article's Creative Commons licence and your intended use is not permitted by statutory regulation or exceeds the permitted use, you will need to obtain permission directly from the copyright holder. To view a copy of this licence, visit http://creativecommons.org/licenses/by/4.0/ The Creative Commons Public Domain Dedication waiver (http://creativecommons.org/publicdomain/zero/1.0/) applies to the data made available in this article, unless otherwise stated in a credit line to the data. 


\section{Background}

Hepatitis B, caused by the hepatitis B virus (HBV) infection, is known to cause several liver diseases including chronic hepatitis $\mathrm{B}(\mathrm{CHB})$, cirrhosis, and hepatocellular carcinoma (HCC) [1, 2]. According to the $2015 \mathrm{WHO}$ report, HBV infection affects $3.5 \%$ of the world population (257 million individuals) and is especially prevalent in Asian populations [3]. Several genome-wide association studies (GWASs) on CHB risk have been conducted on Asian populations and have found that $\mathrm{CHB}$ risk associated loci are typically located in human leukocyte antigen (HLA) regions, such as HLA-DP and $H L A-D Q$ [4-7], in Chinese, Japanese, and Korean populations. According to our previous GWASs, several genes in HLA regions, such as transcription factor 19 (TCF19), and valyl-tRNA synthetase 2 (VARS2)-surfactant associated 2 (SFTA2), euchromatin histone-lysinemethyltransferase 2 (EHMT2), showed significant genetic effects on $\mathrm{CHB}$ susceptibility in a Korean population [59]. Interestingly, genetic variants of $C F B$, found on the nearby gene of EHMT2, have strong association with CHB susceptibility in Chinese studies [10-12].

$C F B$ located on HLA genomic region is essential for regulating $\mathrm{T}$-cell mediated innate immunity in the complement system [13-15]. A number of studies have demonstrated that $C F B$ genetic variants are also associated with several diseases related to innate immune responses, anterior uveitis and Vogt-Koyanagi-Harada disease $[16,17]$. This study conducted association analysis between $C F B$ SNPs and CHB susceptibility to validate genetic effect of $r s 12614$ and identify possible additional causal variants around $r s 12614$ in a Korean population by fine-mapping of $C F B$ region. Furthermore, the genetic risk scores (GRSs) of all known $\mathrm{CHB}$ risk makers were calculated to investigate the cumulative genetic effects of $\mathrm{CHB}$ susceptibility in individuals.

\section{Methods}

\section{Study subjects}

In this study, a total of 1716 subjects which were consist of 955 cases and 761 controls were recruited and investigated for identifying genetic effects on $\mathrm{CHB}$. The 955 patients with $\mathrm{CHB}$ were obtained from the outpatient clinic of the Liver Unit and the Center for Health Promotion at Seoul National University Hospital, Ajou University Medical Center (Suwon, Korea), and Ulsan University Hospital (Ulsan, Korea). Among the CHB patients, 296 patients were also diagnosed with HCC. The 761 population controls (PCs) were provided by Korea BioBank, the Center for Genome Science, Korea Centers for Disease Control and Prevention, and the National Institute of Health. Seropositivity of the hepatitis B surface (HBsAg; Enzygnost ${ }^{\oplus}$ HBsAg 5.0; Dade Behring, Marburg, Germany) over a 6-month period was used for inclusion criterion for diagnosing patients with chronic HBV infection (Supplementary Table 1). The detailed experimental procedures for $\mathrm{HBsAg}$ detection using Enzygnost ${ }^{\oplus} \mathrm{HBsAg} 5.0 \mathrm{Kit}$ assay is described in elsewhere [18]. Diagnosis of $\mathrm{HCC}$ was based on imaging findings of nodules that were larger than $1 \mathrm{~cm}$, showing intense arterial uptake, followed by washout of contrast in the venous-delayed phases, in a 4-phase multi-detector CT scan or dynamic contrast enhanced MRI and/or biopsy [19]. Though individuals with HBsAg (-) and anti-HBc (+) (spontaneously cleared for viral infection) are the best disease controls, individuals with an unknown response to HBV infection were used as the population controls, and some of them still have a chance to $\mathrm{CHB}$ and/or HCC when exposed to HBV. The study protocol complied with the Declaration of Helsinki. The study was approved by the institutional review board of Seoul National University Hospital, Ajou University Medical Center, and Ulsan University Hospital. All the subjects participating in the study provided written informed consent.

\section{SNP genotyping}

Following criteria were adopted for SNP selection: 1) Candidate SNPs of the genomic region around $C F B$ (CFB gene with $2 \mathrm{~kb}$ upstream (to include promoter region) and 500 bp downstream regions; Chr6: 31,911,72131,920,361) were extracted from 1000 genomes Japanese and Han Chinese data, and minor allele frequency (MAF) and linkage disequilibrium (LD) status of the extracted SNPs were calculated. 2) Using NCBI dbSNP, investigate the functional location of the SNPs (upstream variant $(2 \mathrm{~kb}), 5$-prime UTR variant, missense, synonymous-codon, intron variant, downstream variant (500 bp), 3-prime UTR variant) extracted in 1). 3) Based on the 1) and 2), among the SNPs with high LD $\left(r^{2}>\right.$ $0.98)$, SNP with relatively frequent (MAF $>5 \%)$ and functional effect based on the position was selected. And promoter region and non-synonymous SNPs with low frequency $(\mathrm{MAF} \leq 5 \%)$ are additionally selected. As results, 5 tagging SNPs (rs1048709, rs537160, rs541862, rs4151657 and rs2072633) were selected along with 5 non-synonymous SNPs (rs4151667, rs12614, rs641153, rs117314762 and rs45484591). A total of 10 SNPs were genotyped in $955 \mathrm{CHB}$ patients and 761 healthy controls. Genotyping reactions were performed by using BioMark HD system (Fluidigm 192.24. SNPtype ${ }^{\mathrm{Tx}}$, San Francisco, CA, USA). The primer pools were designed for Specific target amplifications, Allele-specific and Locus-specific primers to detect candidate SNPs, and all the primers for 10 investigated SNPs in this study were designed and provided by the manufacturer of Fluidigm system (Fluidigm Corp., San Francisco, CA, USA). The additional workflow was followed by the manufacturer's 
instructions for using the Integrated IFC Controller RX, FC1 Cycler, and EP1 Reader. Signal intensities for genotyping calling were scanned using the EP1 data collection and SNP Genotyping analysis software (Fluidigm Corp., San Francisco, CA, USA). The locations of the investigated SNPs are shown in Supplementary Figure 1A.

\section{Statistical analysis}

LD status of the investigated SNPs were calculated with examination of Lewontin's D' (|D'|) and the LD coefficient r2 between all pairs of bi-allelic loci using Haploview v4.2 (http://www.broadinstitute.org/mpg/haploview) [20]. Comparison of genotype distributions, including MAF and Hardy-Weinberg Equilibrium (HWE), between $\mathrm{CHB}$ patients and controls and and calculating odds ratios (ORs), 95\% confidence intervals, and corresponding $P$-values was carried out with a logistic regression model adjusted for age (continuous value) and sex (male $=0$, female $=1$ ) as covariates using SAS, version 9.4 (SAS Inc., Cary, NC, USA). In corrections for multiple comparisons, Bonferroni correction for multiple testing was applied. Conditional logistic regression analysis was performed to investigate whether the novel significant association signal of investigated SNP was independent or affected by previously known $\mathrm{CHB}$ markers. Allele test based on the allele distribution of each SNP was also performed to assess the detailed genetic effects. Ten previously reported CHB susceptible loci in a Korean population (rs9277535 of HLADPB1; rs3077 of HLA-DPA1; rs2856718 of HLA-DQB1; rs7453920 of HLA-DQB2; rs1419881 of TCF19; rs1265163 of OCT4; rs652888 and rs35875104 of EHMT2; rs9394021 and rs2517459 of VARS2-SFTA) [5-9] were used for the conditional analysis and allele test. Based on the results from allele test, GRSs were calculated. The detailed calculation method for GRSs was described in elsewhere [18].

\section{Results}

\section{Genotyping of CFB genetic variants}

A total of 10 CFB SNPs were selected and genotyped in 1716 Korean subjects, comprised of $955 \mathrm{CHB}$ patients and 761 population controls (Supplementary Table 1). Patients were divided into two subgroups, 659 HCC (-) $\mathrm{CHB}$ cases and $296 \mathrm{HCC}(+) \mathrm{CHB}$ cases. A gene map and LD among investigated SNPs are shown in Supplementary Figure 1A and B. Detailed information on the investigated SNPs, such as chromosome, position, allele, genotype distribution, heterozygosity, and HWE $P$, are presented in Supplementary Table 2.

\section{Association of CFB genetic polymorphisms with CHB risk} In order to investigate the association between $C F B$ genetic polymorphisms and risk of $\mathrm{CHB}$, logistic regression analysis under an additive model was conducted. Analysis results indicated that $r s 12614$ was significantly associated with risk of $\mathrm{CHB}$ even after applying Bonferroni correction for multiple testing $(\mathrm{OR}=0.43, P=5.91 \times$ $10^{-10}, P_{\text {corr }}=2.36 \times 10^{-8}$; Table 1$)$. In order to validate the genetic effects of $r s 12614$, association analysis was conducted using the training and test sets from the subjects in this study (Supplementary Table 3). Additional subgroup analysis was performed to investigate the association between CFB SNPs and CHB-related HCC progression. Again, analysis results found that, rs12614 had significant associations with risk of $\mathrm{CHB}$ in both the $\mathrm{HCC}(-) \mathrm{CHB}$ and the $\mathrm{HCC}(+) \mathrm{CHB}$ subgroups $(P=$ $6.60 \times 10^{-8}$ and $3.10 \times 10^{-6}$, respectively) even after Bonferroni correction was applied for multiple testing $\left(P_{\text {corr }}=2.64 \times 10^{-6}\right.$ and $1.24 \times 10^{-4}$, respectively $)$. However, rs12614 did not show significant genetic effect on CHB-related HCC progression $(P>0.05)$.

\section{Independent genetic effect of rs 12614 on CHB risk}

In order to understand the association between rs12614 and $\mathrm{CHB}$ risk, particularly with respect to independent genetic effect on $\mathrm{CHB}$ susceptibility, this study conducted LD calculations and conditional analysis on 10 previously identified $\mathrm{CHB}$ susceptibility markers (rs9277535 of HLA-DPB1; rs3077 of HLA-DPA1; rs2856718 of HLA-DQB1; rs7453920 of HLA-DQB2; rs1419881 of TCF19; rs1265163 of OCT4; rs652888 and rs35875104 of EHMT2; rs9394021 and rs2517459 of VARS2-SFTA). Supplementary Figure 2 shows the LD plot of $r s 12614$ and the $10 \mathrm{CHB}$ susceptibility markers. The results show that $C F B$ rs 12614 did not display tight LDs with any known, nearby CHB-susceptible loci (pairwise $r^{2} \leq 0.15$; Supplementary Figure 2). In addition, when adjusting for previously identified $\mathrm{CHB}$ markers, rs12614 maintained significant association with CHB risk $(P<0.05$; Table 2$)$, indicating that $r s 12614$ had independent genetic effect on $\mathrm{CHB}$ susceptibility to previously identified $\mathrm{CHB}$ risk markers.

\section{Cumulative genetic effects of CHB susceptible loci}

In order to examine the detailed genetic effects of all 11 CHB susceptible loci including rs12614 (rs12614 of CFB; rs9277535 of HLA-DPB1; rs3077 of HLA-DPA1; rs 2856718 of $H L A-D Q B 1 ; \quad r s 7453920$ of $H L A-D Q B 2$; rs1419881 of TCF19; rs1265163 of OCT4; rs652888 and rs35875104 of EHMT2; rs9394021 and rs2517459 of VARS2-SFTA) in a Korean population, an allele test was conducted for each SNP. The GRSs of the genotypes were calculated using the ORs from allele test (Table 3).

To elucidate the cumulative genetic effects of all 11 CHB loci in the study subjects, the cumulative GRSs were evaluated. The cumulative GRSs ranged from 5.24 (most protected group) to 17.38 (most susceptible 
Table 1 Association of CFB genetic polymorphisms with the risk of CHB and HCC

\begin{tabular}{|c|c|c|c|c|c|c|c|c|c|c|c|c|c|c|c|c|}
\hline \multirow[t]{4}{*}{ Marker } & \multicolumn{5}{|l|}{ MAF } & \multirow{3}{*}{\multicolumn{3}{|c|}{$\begin{array}{l}\text { Comparing groups } \\
\text { CHB vs. PC }\end{array}$}} & & & & & & & & \\
\hline & \multirow{3}{*}{$\begin{array}{l}\begin{array}{l}\text { Total } \\
(n=\end{array} \\
1716)\end{array}$} & \multicolumn{3}{|l|}{$\mathrm{CHB}$} & \multirow{3}{*}{$\begin{array}{l}\text { PC } \\
(n= \\
761)\end{array}$} & & & & \multirow{2}{*}{\multicolumn{3}{|c|}{ HCC (-) vs. PC }} & \multirow{2}{*}{\multicolumn{3}{|c|}{ HCC (+) vs. PC }} & \multirow{2}{*}{\multicolumn{2}{|c|}{$\begin{array}{l}\text { HCC (-) vs. } \\
\text { HCC (+) }\end{array}$}} \\
\hline & & \multirow{2}{*}{$\begin{array}{l}\text { All } \\
\text { CHB } \\
(n= \\
955)\end{array}$} & \multirow{2}{*}{$\begin{array}{l}\text { HCC } \\
(-) \\
(n= \\
659)\end{array}$} & \multirow{2}{*}{$\begin{array}{l}\text { HCC } \\
(+) \\
(n= \\
\text { f) }\end{array}$} & & & & & & & & & & & & \\
\hline & & & & & & $\begin{array}{l}\text { OR } \\
(95 \% \\
\mathrm{Cl}) \\
\end{array}$ & $P^{*}$ & $P_{\text {corr }}^{* *}$ & $\begin{array}{l}\text { OR } \\
(95 \% \\
\mathrm{CI}) \\
\end{array}$ & $P^{*}$ & $P_{\text {corr }}^{* *}$ & $\begin{array}{l}\text { OR } \\
(95 \% \\
\mathrm{CI}) \\
\end{array}$ & $P^{*}$ & $P_{\text {corr }}^{* *}$ & $\begin{array}{l}\text { OR } \\
(95 \% \\
\mathrm{Cl}) \\
\end{array}$ & $P^{*}$ \\
\hline rs4151667 & 0.018 & 0.019 & 0.018 & 0.022 & 0.016 & $\begin{array}{l}1.23 \\
(0.73- \\
2.08)\end{array}$ & 0.42 & - & $\begin{array}{l}1.16 \\
(0.65- \\
2.06)\end{array}$ & 0.61 & - & $\begin{array}{l}1.41 \\
(0.70- \\
2.80)\end{array}$ & 0.34 & - & $\begin{array}{l}0.82 \\
(0.41- \\
1.63)\end{array}$ & 0.58 \\
\hline rs 12614 & 0.078 & 0.053 & 0.054 & 0.048 & 0.112 & $\begin{array}{l}0.43 \\
(0.33- \\
0.57)\end{array}$ & $\begin{array}{l}5.91 \times \\
10^{-10}\end{array}$ & $\begin{array}{l}2.36 \times \\
10^{-8}\end{array}$ & $\begin{array}{l}0.45 \\
(0.33- \\
0.61)\end{array}$ & $\begin{array}{l}6.60 \times \\
10^{-8}\end{array}$ & $\begin{array}{l}2.64 \times \\
10^{-6}\end{array}$ & $\begin{array}{l}0.39 \\
(0.25- \\
0.60)\end{array}$ & $\begin{array}{l}3.10 x \\
10^{-6}\end{array}$ & $\begin{array}{l}1.24 \times \\
10^{-4}\end{array}$ & $\begin{array}{l}1.13 \\
(0.72- \\
1.78)\end{array}$ & 0.58 \\
\hline rs641153 & 0.082 & 0.083 & 0.086 & 0.076 & 0.080 & $\begin{array}{l}1.04 \\
(0.81- \\
1.33)\end{array}$ & 0.74 & - & $\begin{array}{l}1.08 \\
(0.83- \\
1.41)\end{array}$ & 0.54 & - & $\begin{array}{l}0.94 \\
(0.66- \\
1.34)\end{array}$ & 0.75 & - & $\begin{array}{l}1.14 \\
(0.80- \\
1.62)\end{array}$ & 0.45 \\
\hline rs117314762 & 0.015 & 0.013 & 0.014 & 0.010 & 0.018 & $\begin{array}{l}0.67 \\
(0.38- \\
1.17)\end{array}$ & 0.16 & - & $\begin{array}{l}0.73 \\
(0.40- \\
1.34)\end{array}$ & 0.31 & - & $\begin{array}{l}0.54 \\
(0.22- \\
1.32)\end{array}$ & 0.15 & - & $\begin{array}{l}1.35 \\
(0.53- \\
3.45)\end{array}$ & 0.51 \\
\hline rs 1048709 & 0.279 & 0.269 & 0.265 & 0.277 & 0.293 & $\begin{array}{l}0.88 \\
(0.76- \\
1.02)\end{array}$ & 0.11 & - & $\begin{array}{l}0.86 \\
(0.73- \\
1.02)\end{array}$ & 0.09 & - & $\begin{array}{l}0.92 \\
(0.74- \\
1.14)\end{array}$ & 0.47 & - & $\begin{array}{l}0.94 \\
(0.75- \\
1.16)\end{array}$ & 0.58 \\
\hline rs537160 & 0.333 & 0.327 & 0.322 & 0.340 & 0.341 & $\begin{array}{l}0.93 \\
(0.81- \\
1.08)\end{array}$ & 0.39 & - & $\begin{array}{l}0.91 \\
(0.77- \\
1.07)\end{array}$ & 0.26 & - & $\begin{array}{l}0.99 \\
(0.81- \\
1.21)\end{array}$ & 0.95 & - & $\begin{array}{l}0.91 \\
(0.74- \\
1.13)\end{array}$ & 0.43 \\
\hline rs541862 & 0.082 & 0.083 & 0.086 & 0.076 & 0.080 & $\begin{array}{l}1.04 \\
(0.81- \\
1.33)\end{array}$ & 0.74 & - & $\begin{array}{l}1.08 \\
(0.83- \\
1.41)\end{array}$ & 0.54 & - & $\begin{array}{l}0.94 \\
(0.66- \\
1.34)\end{array}$ & 0.75 & - & $\begin{array}{l}1.14 \\
(0.80- \\
1.62)\end{array}$ & 0.45 \\
\hline rs4151657 & 0.323 & 0.335 & 0.341 & 0.321 & 0.307 & $\begin{array}{l}1.13 \\
(0.98- \\
1.30)\end{array}$ & 0.09 & - & $\begin{array}{l}1.16 \\
(0.99- \\
1.36)\end{array}$ & 0.06 & - & $\begin{array}{l}1.06 \\
(0.86- \\
1.30)\end{array}$ & 0.55 & - & $\begin{array}{l}1.09 \\
(0.88- \\
1.34)\end{array}$ & 0.40 \\
\hline rs45484591 & 0.001 & 0.001 & 0.002 & 0.000 & 0.001 & $\begin{array}{l}0.79 \\
(0.11- \\
5.66)\end{array}$ & 0.82 & - & $\begin{array}{l}1.15 \\
(0.16- \\
8.22)\end{array}$ & 0.89 & - & - & - & - & - & - \\
\hline rs2072633 & 0.477 & 0.468 & 0.467 & 0.471 & 0.488 & $\begin{array}{l}0.92 \\
(0.80- \\
1.05)\end{array}$ & 0.25 & - & $\begin{array}{l}0.91 \\
(0.79- \\
1.06)\end{array}$ & 0.26 & - & $\begin{array}{l}0.93 \\
(0.77- \\
1.13)\end{array}$ & 0.50 & - & $\begin{array}{l}0.98 \\
(0.80- \\
1.19)\end{array}$ & 0.85 \\
\hline
\end{tabular}

Significant associations are shown in bold face $(P<0.05)$

MAF minor allele frequency, $C H B$ chronic hepatitis $B, H C C$ hepatocellular carcinoma, $O R$ odds ratio, $C l$ confidence interval

" $P$-value of logistic regression analysis under additive model by adjusting for sex and age as covariates

**P-value after Bonferroni correction for multiple testing

group), and $\mathrm{CHB}$ patients showed significantly higher cumulative GRSs than did the healthy control subjects (Supplementary Table 4 and Fig. 1a). It was found that as cumulative GRSs increased, ORs significantly increased as well. In particular, individuals with GRSs of less than 7 showed an OR of $0.17\left(\log _{10} \mathrm{OR}=-0.77\right)$, while individuals with GRSs of over 14 showed an OR of $3.42\left(\log _{10}\right.$ OR $\left.=0.53\right)$ (Fig. 1b).

\section{Discussion}

Hepatitis B, an infectious disease with a high rate of incidence in Asian populations [1], is a major cause of $\mathrm{CHB}$, liver failure, liver cirrhosis, and HCC development, diseases which often result in death $[21,22]$. Although the mechanisms underlying the different clinical results of HBV infection have not been fully understood, previous studies have linked a diverse range of factors such as viral strain, gender, age of infection, host immune system, and genetic information of the host, with risk of CHB [23]. When viral infection occurs, several immunerelated genes are activated, leading to disease outbreak. According to a GWAS conducted on a Chinese population, a $C F B$ genetic variant had significant association with risk of $\mathrm{CHB}$ [10]. In this study, we aimed to 1) validation of GWAS association signal SNP (CFB rs12614) on CHB susceptibility in a Korean population, and 2) identification of possible additional causal variants around GWAS association signal SNP on CHB susceptibility in a Korean population by fine-mapping of $C F B$ region.

The complement system is composed of over 30 plasma proteins and is activated by microbes or 


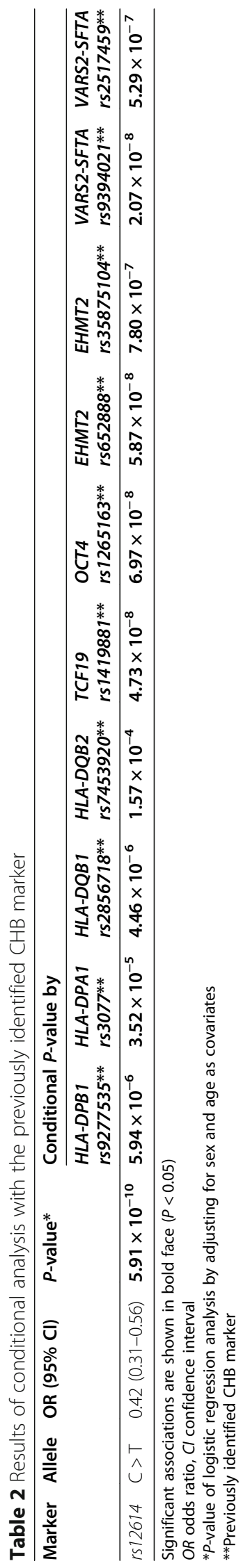


Table 3 Determination of Genetic Risk Score based on Allele test of CHB susceptible loci

\begin{tabular}{|c|c|c|c|c|c|c|}
\hline \multirow[t]{2}{*}{ Gene/Marker } & \multicolumn{2}{|c|}{ Genotype distribution } & \multicolumn{3}{|c|}{ Allele test } & \multirow[t]{2}{*}{$\mathrm{GRS}^{\mathrm{b}}$} \\
\hline & CHB $(n=955)$ & $\mathrm{PC}(n=761)$ & Allele $^{a}$ & OR $(95 \% \mathrm{Cl})$ & $P$-value & \\
\hline \multirow[t]{3}{*}{ CFB/rs 12614} & CC(829) & CC(550) & C & 1 & - & 1 \\
\hline & $\mathrm{CT}(91)$ & $\mathrm{CT}(142)$ & $\mathrm{T}$ & $0.44(0.33-0.57)$ & $6.46 \times 10^{-10}$ & 0.44 \\
\hline & $\Pi(3)$ & $\Pi(7)$ & & & & 0.22 \\
\hline \multirow[t]{3}{*}{ HLA-DPB1/rs9277535 } & GG(420) & GG(184) & G & 1 & - & 1 \\
\hline & $\mathrm{GA}(428)$ & GA(384) & A & $0.49(0.43-0.56)$ & $9.47 \times 10^{-24}$ & 0.49 \\
\hline & $\mathrm{AA}(107)$ & $\mathrm{AA}(193)$ & & & & 0.25 \\
\hline \multirow[t]{3}{*}{ HLA-DPA1/rs3077 } & GG(489) & GG(221) & G & 1 & - & 1 \\
\hline & GA(382) & GA(385) & A & $0.48(0.41-0.55)$ & $1.84 \times 10^{-24}$ & 0.48 \\
\hline & $\mathrm{AA}(84)$ & $\mathrm{AA}(155)$ & & & & 0.24 \\
\hline \multirow[t]{3}{*}{ HLA-DQB1/rs2856718c } & CC(226) & CC(263) & C & 1 & - & 1 \\
\hline & CT(418) & CT(373) & $\mathrm{T}$ & $1.72(1.50-1.97)$ & $3.10 \times 10^{-15}$ & 1.72 \\
\hline & $\Pi \pi(311)$ & $\Pi(125)$ & & & & 3.44 \\
\hline \multirow[t]{3}{*}{$H L A-D Q B 2 / r s 7453920^{\circ}$} & GG(743) & $G G(461)$ & G & 1 & - & 1 \\
\hline & GA(196) & GA(275) & A & $0.49(0.41-0.60)$ & $1.07 \times 10^{-13}$ & 0.49 \\
\hline & $\mathrm{AA}(16)$ & $\mathrm{AA}(25)$ & & & & 0.25 \\
\hline \multirow[t]{3}{*}{ TCF19/rs $1419881^{c}$} & $\Pi(419)$ & $\Pi(270)$ & $\mathrm{T}$ & 1 & - & 1 \\
\hline & $\mathrm{TC}(424)$ & $\mathrm{TC}(361)$ & $C$ & $0.74(0.64-0.85)$ & $3.46 \times 10^{-5}$ & 0.74 \\
\hline & CC(112) & CC(130) & & & & 0.37 \\
\hline \multirow[t]{3}{*}{ EHMT2/rs652888 } & $\Pi T(610)$ & $\pi(565)$ & $\mathrm{T}$ & 1 & - & 1 \\
\hline & $\mathrm{TC}(300)$ & TC(188) & C & $1.65(1.37-1.99)$ & $5.14 \times 10^{-8}$ & 1.65 \\
\hline & $\mathrm{CC}(45)$ & $C C(8)$ & & & & 3.3 \\
\hline \multirow[t]{3}{*}{ OCT4/rs1265163 } & $G G(401)$ & GG(392) & G & 1 & - & 1 \\
\hline & GC(439) & GC(299) & C & $1.32(1.14-1.53)$ & $1.36 \times 10^{-4}$ & 1.32 \\
\hline & CC(114) & $\mathrm{CC}(70)$ & & & & 2.64 \\
\hline \multirow[t]{3}{*}{ EHMT2/rs35875104 } & TТ(878) & $\Pi(650)$ & $\mathrm{T}$ & 1 & - & 1 \\
\hline & $\mathrm{TC}(75)$ & $\mathrm{TC}(108)$ & C & $0.53(0.39-0.71)$ & $2.42 \times 10^{-5}$ & 0.53 \\
\hline & $\mathrm{CC}(2)$ & $\mathrm{CC}(3)$ & & & & 0.27 \\
\hline \multirow[t]{3}{*}{ VARS2-SFTA/rs9394021 } & $\mathrm{AA}(303)$ & $\mathrm{AA}(189)$ & A & 1 & - & 1 \\
\hline & $A G(471)$ & $A G(368)$ & G & $0.73(0.64-0.84)$ & $1.10 \times 10^{-5}$ & 0.73 \\
\hline & GG(177) & GG(203) & & & & 0.37 \\
\hline \multirow[t]{3}{*}{ VARS2-SFTA/rs $2517459^{\circ}$} & GG(809) & $G G(560)$ & G & 1 & - & 1 \\
\hline & GA(139) & GA(193) & A & $0.53(0.43-0.67)$ & $3.71 \times 10^{-8}$ & 0.53 \\
\hline & $\mathrm{AA}(6)$ & $\mathrm{AA}(8)$ & & & & 0.27 \\
\hline
\end{tabular}

Significant associations are shown in bold face $(P<0.05)$

CHB chronic hepatitis B, PC population control, OR odds ratio, $\mathrm{Cl}$ confidence interval, GRS genetic risk score

${ }^{a}$ Major and minor alleles were determined in all study subjects

${ }^{b}$ GRS was calculated by multiplying the number of minor alleles by effect size (OR) of the SNP

cPreviously identified CHB marker in Korean population

antibodies which attached to microbes or other antigens $[24,25]$. This system is an innate immune system that helps operate rapid responses against pathogenic invasions by opsonizing or recruiting inflammatory cells or pathogen lysis [26]. The complement activations occur through three pathways: the classical pathway, the lectin pathway and the alternative pathway. These pathways are worked through a cascade of enzymes reaction [25, 27]. CFB is essential to activate the complement system, particularly the alternative pathway that is against microbe invasion which includes viruses [28].

Previous Chinese studies have identified $C F B$ genetic variants which have genetic effect on $\mathrm{CHB}$ risk. The most significant association was identified at rs12614 of 
A.

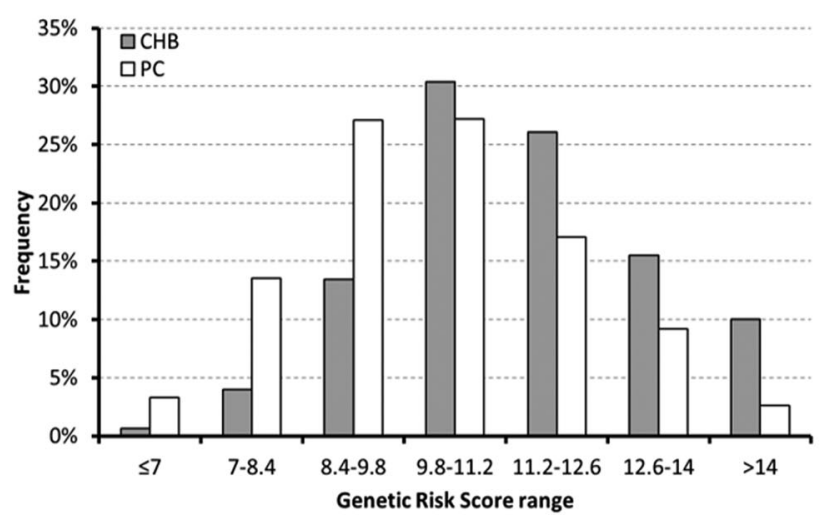

B.

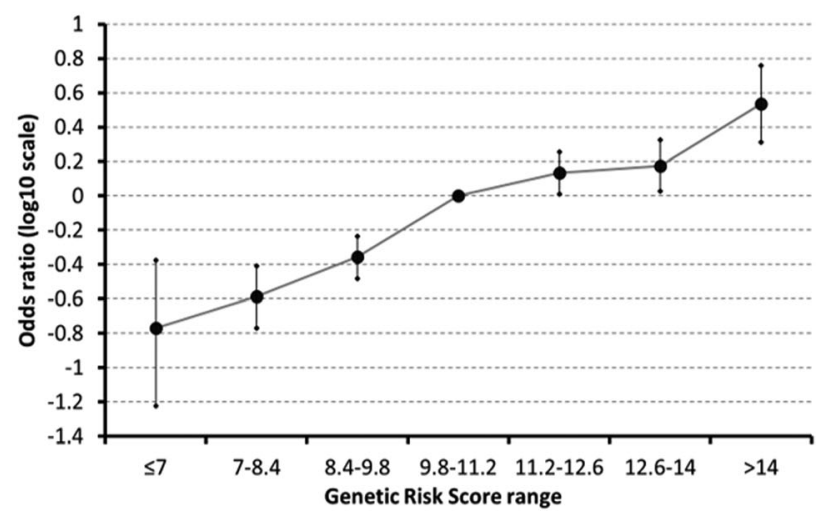

Fig. 1 Combined genetic effects of eleven CHB genetic markers on the risk of CHB. a Comparison of GRS between CHB group and PC group. b Odds ratios of different GRS range in log10 scale. Median genetic risk score range (9.8-11.2) is used as a reference. CHB, chronic hepatitis B; PC, population control; GRS, genetic risk score

CFB $\left(P=1.28 \times 10^{-34}-4.0 \times 10^{-3}\right)[10,11]$. In this study, rs12614 showed the same direction of genetic effect as found in previous Chinese studies. In order to validate the associations, we have conducted the validation analysis of $C F B$ genetic variant, rs12614, using random sampling of the training and test sets from the subjects. As result, all training sets showed significant results and although not all test sets showed significant results due to small sample sizes in test sets, the trends of effects were the same directions (Supplementary Table 3). Moreover, $C F B$ rs 12614 was significantly associated with risk of $\mathrm{CHB}$ in the $\mathrm{HCC}(-) \mathrm{CHB}$ and the $\mathrm{HCC}(+) \mathrm{CHB}$ groups $\left(P=6.60 \times 10^{-8}\right.$ and $3.10 \times 10^{-6}$, respectively). However, there was no significant genetic effect on CHB-related HCC progression. Additionally, the rs12614 C>T T allele was more frequently observed in the $\mathrm{PC}$ group than the $\mathrm{CHB}$ patients with a significance $(\mathrm{OR}=0.43$, $\left.P_{\text {corr }}=2.36 \times 10^{-8}\right)$. Considering that individuals with the non-synonymous variant (rs12614 $\mathrm{T}$ allele) had significantly higher CFB expression than those with the rs $12614 \mathrm{C}$ allele in the Chinese study, it can be seen that the rs12614 may affect immune response by influencing the complement system when viral infection occurs [10].

The rs 12614 which is located on coding region of $C F B, \mathrm{C}$ to $\mathrm{T}$ allele change causes the amino acid change, arginine to tryptophan. To predict the effects of the rs12614 amino acid change, we conducted in silico analysis using the PolyPhen-2 program (http://genetics.bwh. harvard.edu/pph2/index.shtml) [29]. The results demonstrated that this amino acid change is predicted to be probably damaging that means this substitution might be damaging with high confidence (Supplementary Figure 3A, [29]). Amino acid alignment from the program, arginine at position 32 is highly conserved among species (Supplementary Figure 3B). Additionally, protein structure prediction was performed using CFSSP: Chou \& Fasman Secondary Structure Prediction Server (http:// www.biogem.org/tool/chou-fasman/index.php) [30]. Changes in protein secondary structure of rs 12614 region, from coil structure to helix structure, by amino acid change from arginine to tryptophan were predicted. (Supplementary Figure 4). Protein function is closely related to the structure so that amino acids residue substitution can modify functional sites or protein interactions. And also disease-causing substitutions are more likely to occur at positions that is conserved throughout evolution [31], the rs12614 $\mathrm{C}$ to $\mathrm{T}$ allele substitution may affect CFB functions. Because the alternative pathway is important to against pathogen invasion, an amino acid change in $C F B$ important in the alternative pathway may affect the immune system to against hepatitis $B$ virus invasion.

Some individuals are more susceptible to diseases while others are less susceptible. Identification of the genetic background is key to understand differences in individuals' disease susceptibility, and that can potentially lead to the targeting of preventive measures at those who are at greatest risk [32]. The results of the conditional analysis conducted on the 10 previously identified markers indicated that $r s 12614$ can be used as a novel causal variant of $\mathrm{CHB}$ susceptibility. To elucidate its cumulative genetic effects, we used odd ratios of rs12614 and previously identified 10 CHB markers. Consequently, CHB group showed higher GRSs than the PC group and the higher genetic risk scores range indicated higher odds ratios. These implies $\mathrm{CHB}$ patients are more likely to have higher scores than controls.

There is a sampling limitation in this study. While the ideal subjects for the control groups would be the people who are HBsAg (-) and anti-HBc (+) (spontaneously 
cleared), we used population controls with unknown responses to HBV infection. And some individuals in the control group still have a chance of progression to $\mathrm{CHB}$ when exposed to HBV. Although using the population controls in a case-control study may reduce statistical power, it is useful when it is difficult to obtain a sufficient number of disease controls.

\section{Conclusions}

A non-synonymous variant, $r s 12614$ (Arg32Trp) of $C F B$ was found to have significant associations with risk of $\mathrm{CHB}$ in a Korean population. Moreover, genetic effect of rs 12614 on CHB risk was independent of all known CHB risk loci, and rs12614 can be used as possible causal variant of CHB susceptibility. Therefore, the results from this study may help in understanding and predicting genetic susceptibility to CHB in a Korean population.

\section{Supplementary Information}

The online version contains supplementary material available at https://doi. org/10.1186/s12881-020-01177-w.

Additional file 1: Supplementary Figure 1. Gene map and LD plot of CFB. A. Gene map of CFB (complement factor B) on chromosome 6p21.33 (6 kb). Black blocks mean coding exons, and white blocks mean $5^{\prime}$ and $3^{\prime}$ UTRs. B. Linkage disequilibrium (LD) plot of CFB polymorphisms. Numbers in color boxes indicate $\left|D^{\prime}\right|$ values.

Additional file 2: Supplementary Figure 2. LD plot of rs 12614 and previously identified 10 CHB markers. LD plot of CFB rs 12614 and previously identified $10 \mathrm{CHB}$ susceptibility markers. Numbers in black and white boxes indicate $r^{2}$ values. LD structure was constructed by Haploview software.

Additional file 3: Supplementary Figure 3. In silico analysis of CFB rs 12614. A. To predict amino acid change (Arg32Trp) in CFB rs12614 affects protein function, HumDiv model analysis was conducted using PolyPhen-2 v2.2.2r398. Arg32Trp mutation is predicted to be probably damaging with a score of 0.985 (http://genetics.bwh.harvard.edu/pph2/ index.shtml). B. Amino acids sequence alignment about diverse species of CFB rs 12614 was conducted using PolyPhen-2 v2.2.2r398 according to UniProtKB/UniRef100 (http://genetics.bwh.harvard.edu/pph2/index.shtml). Shown are 75 amino acids surrounding the mutation position (marked with a black box).

Additional file 4: Supplementary Figure 4. Secondary structure prediction of CFB. To predict protein secondary structure when CFB allele change, CFSSP: Chou \& Fasman Secondary Structure Prediction Server (http://www.biogem.org/tool/chou-fasman/index.php) was used. (A) Secondary structure of $C$ allele (arginine) and (B) $T$ allele (tryptophan) in CFB rs 12614. $\mathrm{H}, \mathrm{E}, \mathrm{T}$, and $\mathrm{C}$ indicate helix structure, sheet structure, turn and coil structure, respectively.

Additional file 5: Supplementary Table 1. Characteristics of study subjects.

Additional file 6: Supplementary Table 2. Genotype distribution of investigated CFB genetic polymorphisms among subjects investigated in this study.

Additional file 7: Supplementary Table 3. Association analysis of rs 12614 using the Training and Test sets.

Additional file 8: Supplementary Table 4. Combined genetic effects of eleven CHB susceptible loci.

\section{Abbreviations}

CHB: Chronic hepatitis B; CFB: Complement factor B; SNP: Single nucleotide polymorphism; GRSs: Genetic risk scores; HBV: Hepatitis B virus;
HCC: Hepatocellular carcinoma; GWASs: Genome-wide association studies; HLA: Human leukocyte antigen; TCF19: Transcription factor 19; VARS2-

SFTA2: Valyl-tRNA synthetase 2-surfactant associated 2; EHMT2: Euchromatin histone-lysine-methyltransferase 2; PC: Population control; MAF: Minor allele frequency; LD: Linkage disequilibrium; HWE: Hardy-Weinberg Equilibrium; ORs: Odds ratios

\section{Acknowledgements}

The authors would like to thank to the patients and their families.

\section{Authors' contributions}

Conceptualization: HDS, YJK; methodology: HDS, YJK; investigation: JYS, JGS; formal analysis: JYS, JGS, BJY, SN, HSC, LHK, JOK; drafting of the manuscript: JYS, JGS; reviewing and editing the manuscript: BJY, HDS, YJK; all authors read and approved the final version of the manuscript.

\section{Funding}

This research was supported by Basic Science Research Program through the National Research Foundation of Korea (NRF) funded by the Ministry of Education (Grant No. 2017R1D1A1B03030763), the Ministry of Education, Science and Technology (NRF-2015R1A2A1A15053987), and grants from the Korea Health Technology R\&D Project through the Korea Health Industry Development Institute (KHIDI) funded by the Ministry of Health \& Welfare, Republic of Korea (Grant No. HI16C1074) and Yuhan Corporation (Grant No. 800-20170050).

\section{Availability of data and materials}

All statistic data generated or analyzed during this study are included in this published article and its supplementary information files.

\section{Ethics approval and consent to participate}

The study was approved by the institutional review board of Seoul National University Hospital, Ajou University Medical Center, and Ulsan University Hospital and performed in accordance with the principles expressed in the Declaration of Helsinki. All the subjects participating in the study provided written informed consent.

\section{Consent for publication}

Not applicable.

\section{Competing interests}

The authors declare that they have no competing interests.

\section{Author details}

${ }^{1}$ Current address: Department of Core Technology, R\&D Center, LG Household \& Healthcare (LG H\&H), Seoul 07795, South Korea. ²Department of Life Science, Sogang University, Seoul 04107, Republic of Korea. ${ }^{3}$ Research Institute for Basic Science, Sogang University, Seoul 04107, Republic of Korea. ${ }^{4}$ Department of Genetic Epidemiology, SNP Genetics Inc., Seoul 04107, Republic of Korea. ${ }^{5}$ Department of Internal Medicine and Liver Research Institute, Seoul National University, 103 Daehak-ro, Jongno-gu, Seoul 03080, Republic of Korea

Received: 24 July 2020 Accepted: 23 November 2020

Published online: 17 December 2020

\section{References}

1. Gish RG, Given BD, Lai CL, Locarnini SA, Lau JY, Lewis DL, Schluep T. Chronic hepatitis B: virology, natural history, current management and a glimpse at future opportunities. Antivir Res. 2015;121:47-58.

2. Korean Association for the Study of the Liver (KASL): KASL clinical practice guidelines: management of chronic hepatitis B. Clin Mol Hepatol. 2016;22(1): $18-75$.

3. Zhu RX, Seto WK, Lai CL, Yuen MF. Epidemiology of hepatocellular carcinoma in the Asia-Pacific region. Gut Liver. 2016;10(3):332-9.

4. Nishida N, Sawai H, Matsuura K, Sugiyama M, Ahn SH, Park JY, Hige S, Kang $J$ H, Suzuki K, Kurosaki M, et al. Genome-wide association study confirming association of HLA-DP with protection against chronic hepatitis $B$ and viral clearance in Japanese and Korean. PLoS One. 2012;7(6):e39175.

5. Kim YJ, Kim HY, Lee JH, Yu SJ, Yoon JH, Lee HS, Kim CY, Cheong JY, Cho SW, Park NH, et al. A genome-wide association study identified new variants 
associated with the risk of chronic hepatitis B. Hum Mol Genet. 2013;22(20): 4233-8.

6. Zhu M, Dai J, Wang C, Wang Y, Qin N, Ma H, Song C, Zhai X, Yang Y, Liu J, et al. Fine mapping the $\mathrm{MHC}$ region identified four independent variants modifying susceptibility to chronic hepatitis B in Han Chinese. Hum Mol Genet. 2016;25(6):1225-32.

7. Mbarek H, Ochi H, Urabe Y, Kumar V, Kubo M, Hosono N, Takahashi A, Kamatani Y, Miki D, Abe H, et al. A genome-wide association study of chronic hepatitis B identified novel risk locus in a Japanese population. Hum Mol Genet. 2011;20(19):3884-92.

8. Cheong HS, Lee JH, Yu SJ, Yoon JH, Lee HS, Cheong JY, Cho SW, Park NH, Park BL, Namgoong S, et al. Association of VARS2-SFTA2 polymorphisms with the risk of chronic hepatitis B in a Korean population. Liver Int. 2015; 35(8):1934-40

9. Shin JG, Cheong HS, Lee K, Ju BG, Lee JH, Yu SJ, Yoon JH, Cheong JY, Cho SW, Park NH, et al. Identification of novel OCT4 genetic variant associated with the risk of chronic hepatitis B in a Korean population. Liver Int. 2017; 37(3):354-61.

10. Jiang DK, Ma XP, Yu H, Cao G, Ding DL, Chen H, Huang HX, Gao YZ, Wu XP, Long XD, et al. Genetic variants in five novel loci including CFB and CD40 predispose to chronic hepatitis B. Hepatology. 2015;62(1):118-28.

11. Li Y, Si L, Zhai Y, Hu Y, Hu Z, Bei JX, Xie B, Ren Q, Cao P, Yang F, et al. Genome-wide association study identifies 8p21.3 associated with persistent hepatitis B virus infection among Chinese. Nat Commun. 2016;7:11664.

12. Chen H, Sun J, Zhou B, Peng J, Xie Q, Liang X, Fan R, Conran C, Xu J, Ji Y, et al. A missense variant in complement factor B (CFB) is a potential predictor of 24-week off-treatment response to PeglFNalpha therapy in Chinese HBeAg-positive chronic hepatitis B patients. Aliment Pharmacol Ther. 2020;51(4):469-78.

13. Rutkowski MJ, Sughrue ME, Kane AJ, Mills SA, Parsa AT. Cancer and the complement cascade. Mol Cancer Res. 2010;8(11):1453-65.

14. Degn SE, Jensenius JC, Thiel S. Disease-causing mutations in genes of the complement system. Am J Hum Genet. 2011;88(6):689-705.

15. Kwan WH, van der Touw W, Heeger PS. Complement regulation of T cell immunity. Immunol Res. 2012;54(1-3):247-53.

16. Yang MM, Lai TY, Tam PO, Chiang SW, Ng TK, Liu K, Pang CP. Association of C2 and CFB polymorphisms with anterior uveitis. Invest Ophthalmol Vis Sci. 2012;53(8):4969-74.

17. Yang M, Fan JJ, Wang J, Zhao Y, Teng Y, Liu P. Association of the C2-CFB locus with non-infectious uveitis, specifically predisposed to Vogt-KoyanagiHarada disease. Immunol Res. 2016;64(2):610-8.

18. Shin JG, Cheong HS, Kim JY, Lee JH, YU SJ, Yoon JH, Cheong JY, Cho SW, Park NH, Namgoong S, et al. Identification of additional EHMT2 variant associated with the risk of chronic hepatitis B by GWAS follow-up study. Genes Immun. 2019;20(1):1-9.

19. Bruix J, Sherman M. Management of hepatocellular carcinoma: an update. Hepatology. 2011;53(3):1020-2.

20. Barrett JC, Fry B, Maller J, Daly MJ. Haploview: analysis and visualization of LD and haplotype maps. Bioinformatics. 2005;21(2):263-5.

21. El-Serag HB, Rudolph KL. Hepatocellular carcinoma: epidemiology and molecular carcinogenesis. Gastroenterology. 2007;132(7):2557-76.

22. Yu SJ. A concise review of updated guidelines regarding the management of hepatocellular carcinoma around the world: 2010-2016. Clin Mol Hepatol. 2016;22(1):7-17.

23. Wang FS. Current status and prospects of studies on human genetic alleles associated with hepatitis B virus infection. World J Gastroenterol. 2003;9(4): $641-4$.

24. Abbas AK, Lichtman AH, Pillai S. Cellular and molecular immunology. 7th ed. Philadelphia: Elsevier/Saunders; 2012.

25. Dunkelberger JR, Song WC. Complement and its role in innate and adaptive immune responses. Cell Res. 2010;20(1):34-50.

26. Woodruff TM, Ager RR, Tenner AJ, Noakes PG, Taylor SM. The role of the complement system and the activation fragment $\mathrm{C} 5 \mathrm{a}$ in the central nervous system. NeuroMolecular Med. 2010;12(2):179-92.

27. Sarma VJ, Huber-Lang M, Ward PA. Complement in lung disease. Autoimmunity. 2006:39(5):387-94

28. Rawal N, Pangburn MK. Structure/function of C5 convertases of complement. Int Immunopharmacol. 2001;1(3):415-22.

29. Adzhubei I, Jordan DM, Sunyaev SR. Predicting functional effect of human missense mutations using PolyPhen-2. Curr Protoc Hum Genet. 2013; Chapter 7(Unit7):20.
30. Kumar TA. CFSSP: Chou and Fasman secondary structure prediction server Wide Spectrum. 2013;1 (9):15-9.

31. Ng PC, Henikoff S. Predicting the effects of amino acid substitutions on protein function. Annu Rev Genomics Hum Genet. 2006;7:61-80.

32. Chapman SJ, Hill AV. Human genetic susceptibility to infectious disease. Nat Rev Genet. 2012;13(3):175-88.

\section{Publisher's Note}

Springer Nature remains neutral with regard to jurisdictional claims in published maps and institutional affiliations.
Ready to submit your research? Choose BMC and benefit from:

- fast, convenient online submission

- thorough peer review by experienced researchers in your field

- rapid publication on acceptance

- support for research data, including large and complex data types

- gold Open Access which fosters wider collaboration and increased citations

- maximum visibility for your research: over $100 \mathrm{M}$ website views per year

At BMC, research is always in progress.

Learn more biomedcentral.com/submissions 